\title{
Comparing the structure and function of social-cognition-related brain areas in bisexual, heterosexual, and homosexual women and men
}

\author{
Klimaj, V. ${ }^{1,2, *}$, Safron, A ${ }^{1,3,4}$, Sylva, D. ${ }^{5}$, Rosenthal, A.M. ${ }^{5}$, Li, M. ${ }^{6,7,8}$, Walter, M. ${ }^{6,7,8,9}$ Bailey, \\ J.M. ${ }^{10}$
}

${ }^{1}$ Cognitive Science Program, Bloomington, IN, United States

${ }^{2}$ Department of Informatics, Indiana University, Bloomington, IN, U.S.

${ }^{3}$ Kinsey Institute, Indiana University, Bloomington, IN, United States

${ }^{4}$ Center for Psychedelic and Consciousness Research, Department of Psychiatry \& Behavioral

Sciences, Johns Hopkins University School of Medicine, Baltimore, MD

${ }^{5}$ Department of Psychiatry, Kaiser Permanente, US

${ }^{6}$ Clinical Affective Neuroimaging Laboratory, Leibniz Institute for Neurobiology, Magdeburg,

Germany

${ }^{7}$ Otto-von-Guericke-University, Magdeburg, Germany

${ }^{8}$ Department of Psychiatry and Psychotherapy, University of Tuebingen, Tuebingen, Germany

${ }^{9}$ Department of Psychiatry and Psychotherapy, Jena University Hospital, Jena, Germany

${ }^{10}$ Department of Psychology, Northwestern University, Evanston, IL, United States

\begin{abstract}
A small number of studies have examined neuroanatomical differences between heterosexual and homosexual men and women. These studies have yielded mixed support for the hypothesis that homosexual individuals possess sex-atypical neural anatomy. However, in addition to differing along dimensions of sex-typicality, non-heterosexual individuals' brains may be different in other ways, potentially as a result of differences in experience. One way in which sexual minorities may differ from others is in their social experiences. Bisexual individuals in particular may occupy unique social niches and experience complex social environments as a result of sexual and romantic interactions with both men and women, and potentially also in terms of having a less-widely-recognized sexual identity than heterosexual and homosexual individuals. Based on this idea, we hypothesized that bisexual individuals may show increased gray matter volume and activity in two social-cognition-related areas of the brain: the right temporoparietal junction (rTPJ) and the dorsomedial prefrontal cortex (dmPFC). Contrary to our hypotheses, neither brain structure nor brain activity in the rTPJ and dmPFC were
\end{abstract}


significantly greater in bisexual individuals than in heterosexual and homosexual individuals. Instead, we found larger rTPJ volumes in heterosexual women than in homosexual women. We also found larger relative volumes in the dmPFC in women than in men, consistent with a recent large-scale study of sex differences, and potentially indicative of sex and gender differences in social cognition.

Keywords: sexual orientation, bisexual, homosexual, heterosexual, sex differences, neuroanatomy, gender differences, social cognition, theory of mind

\section{Introduction}

\section{Bisexuality and social cognition}

Bisexual individuals occupy a unique social niche. Unlike heterosexual and homosexual individuals (who we refer to here as "monosexuals"), bisexuals are attracted to both men and women, and many have romantic and sexual relationships with both men and women. As a result of their wider range of partners and attractions, bisexuals may experience more variety and complexity in their social worlds (Anderson \& McCormack, 2016; Diamond, 2008). For example, bisexual individuals who have relationships with both men and women may encounter a wider range of gender-related social scripts in intimate contexts. They may also have relationships with individuals of a wider range of sexual orientations as compared to heterosexual and homosexual individuals. A bisexual woman may date lesbian women, other bisexual women, heterosexual men, or bisexual men, whereas a heterosexual woman may date heterosexual (and potentially bisexual) men. Bisexuals may also experience more complexity than heterosexual and homosexual individuals in terms of their social identities (Galupo et al., 2015). Depending on factors such as the gender of a current partner, bisexual individuals may often mistakenly be assumed to be either heterosexual or homosexual. Additionally, while 
"heterosexual" and "homosexual" (or "straight" and "gay/lesbian") are widely recognized sexual orientation categories, bisexuality is often overlooked as an identity (Yoshino, 2000).

The relative lack of recognition of bisexuality as a sexual orientation has been studied from a public health perspective (Chan et al., 2020; Feinstein \& Dyar, 2017). However, there is less research to answer questions on interactions between sexuality, sociality, personality, identity, and other factors from a broader psychological perspective. Are there cases in which particular personality traits influence a person's tendency to explore novel attractions? What factors influence changes in a person's attraction patterns throughout life (Diamond, 2008; Diamonond et al $_{-} .2$ 20 2017$)$ ? How might the brains of individuals with differing sexual attractions reflect other traits that might be related to sexuality? Our focus in this study will be on the last question, with a particular focus on what the brains of bisexual individuals may suggest about their social cognition. Although some existing research has shown differences in empathy and emotion recognition between heterosexual and homosexual men and women (Lübke et al., 2019; Nettle, 2007; Perry et al., 2013; Rahman et al., 2004; Ruben et al., 2014), comparing neural markers of complex social cognition between bisexuals and monosexuals is a novel research approach.

\section{Regions of interest: right temporoparietal junction (rTPJ) and dorsomedial prefrontal cortex (dmPFC)}

Brain structure and activity can either reflect or contribute to differences in cognition and behavior (Abbot, 1916; Fernald, 2003; Fjell \& Walhovd, 2010; Kolb \& Gibb, 2011). If bisexual individuals encounter more complex social niches than monosexuals—e.g. navigating romantic and sexual situations involving both women and men — they may exhibit neural differences that reflect this complexity. Individuals who have strong motivations for social bonding (ones that 
may be neurally-influenced) may also be more likely to explore bisexual attractions (Fleischman et al., 2014).

Based on these potential sources of social difference in bisexuals, we predicted that two brain regions would show a distinct pattern in bisexuals: the right temporoparietal junction (rTPJ) and the dorsomedial prefrontal cortex (dmPFC) (described in more detail below). Specifically, we hypothesized that bisexuals would show larger gray matter volumes in the rTPJ and dmPFC than homosexual and heterosexual individuals, as well as more activity in these areas towards stimuli featuring either men and women than would monosexuals.

A number of studies have identified brain areas that tend to become active when individuals engage in tasks related to social cognition. These studies have focused on identifying regions that are particularly active when individuals are engaged in theory of mind, which involves thinking about and understanding others' beliefs, intentions, and mental states (Carrington \& Bailey, 2009; Hassabis et al., 2014; Koster-Hale et al., 2017; Saxe, 2006; Saxe \& Powell, 2006; Schurz et al., 2014). Across such studies, the two brain areas that appear to be most consistently associated with social cognition and theory of mind are the right temporoparietal junction (rTPJ) and the dorsomedial prefrontal cortex (dmPFC) (Bzdok et al., 2013; Lieberman et al., 2019; Saxe \& Kanwisher, 2003; Saxe \& Powell, 2006; Saxe \& Wexler, 2005; Van Overwalle, 2009; Wagner et al., 2012).

Activation of the rTPJ is specifically associated with inferring the mental states of others, where this capacity is known as "theory of mind" (Gweon et al., 2012; Saxe \& Wexler, 2005). Activation of the dmPFC has been associated with modeling other persons as well as the ability to share attentional focus on an external task or object with another person (Hassabis et al., 2014; Saxe, 2006). This joint attentional ability may be at the center of uniquely human social 
cognition, allowing individuals to understand each other's intentions and plans (Cook, 2018; Tomasello et al., 2005). Based on these functional associations, we focused on the rTPJ and $\mathrm{dmPFC}$ as regions of interest in testing whether bisexuality may be associated with more complex and elaborate social cognition.

\section{Method}

\section{Participants}

We recruited participants for a functional neuroimaging study involving fMRI assessment of reward-related responses to erotic stimuli. Results for these portions of the study were reported in previous publications (Safron et al., 2018, 2017). Participants were 26 heterosexual women, 26 bisexual women, 24 homosexual women, 26 heterosexual men, 28 bisexual men, and 25 homosexual men (155 participants total) recruited using online advertisements.

Advertisements sought paid participants for a neuroimaging study of sexual orientation and arousal. All potential participants were screened for inclusion using online questionnaires asking about sexual orientation, sexual interests, personality, and medical eligibility for MRI/fMRI research. Bisexual participants were required to have had at least one romantic partner (of 3+ months) of each sex and at least two sexual partners of each sex. Heterosexual and homosexual participants also matched these criteria for their preferred sex. All methods were approved by the Institutional Review Board of Northwestern University and carried out in accordance with its guidelines, and each participant provided informed consent for each part of the study.

Table 1 presents distributions of demographic information including participants' Kinsey scores, age, and race. Sexual orientation was assessed by both self-reported sexual identity, as 
well as via a modified Kinsey scale (Kinsey, Pomeroy, \& Martin, 1948). Participants were asked about sexual fantasies experienced in the last year as well as throughout adulthood (Chivers et al. 2004, 2007). Responses were recorded on a scale ranging from 0 to 6 , where 0 corresponds to an exclusive heterosexual orientation, and 6 corresponds to an exclusive homosexual orientation. Each participant's modified Kinsey score was obtained by averaging their responses to questions regarding adulthood and the past year.

Table 1: Participants Demographics: Age, Race, and Kinsey Score

\begin{tabular}{|c|c|c|c|c|c|c|}
\hline & \multicolumn{3}{|l|}{ Men } & \multicolumn{3}{|l|}{ Women } \\
\hline & Heterosexual & Bisexual & Homosexual & Heterosexual & Bisexual & Homosexual \\
\hline Age & $\begin{array}{l}32.3 \\
\mathrm{SD}=6.75 \\
\text { range }=25-48\end{array}$ & $\begin{array}{l}37.5 \\
\mathrm{SD}=8.32 \\
\text { range }=26-50\end{array}$ & $\begin{array}{l}33.1 \\
\mathrm{SD}=6.5 \\
\text { range }=26-50\end{array}$ & $\begin{array}{l}29.6 \\
\mathrm{SD}=5.99 \\
\text { range }=25-46\end{array}$ & $\begin{array}{l}30.3 \\
\mathrm{SD}=6.41 \\
\text { range }=21-48\end{array}$ & $\begin{array}{l}29.0 \\
\mathrm{SD}=3.12 \\
\text { range }=25-38\end{array}$ \\
\hline Race (Caucasian/Other) & $62 \% / 38 \%$ & $54 \% / 46 \%$ & $71 \% / 29 \%$ & $60 \% / 40 \%$ & $73 \% / 27 \%$ & $79 \% / 31 \%$ \\
\hline Kinsey Score & $\begin{array}{l}0.4 \\
\mathrm{SD}=0.46 \\
\text { range }=0-1.5\end{array}$ & $\begin{array}{l}3.2 \\
\mathrm{SD}=0.85 \\
\text { range }=2-4.5\end{array}$ & $\begin{array}{l}5.7 \\
S D=0.46 \\
\text { range }=5-6\end{array}$ & $\begin{array}{l}0.8 \\
S D=0.6 \\
\text { range }=0-2\end{array}$ & $\begin{array}{l}2.63 \\
S D=0.7 \\
\text { range }=2-4.5\end{array}$ & $\begin{array}{l}5.2 \\
S D=0.68 \\
\text { range }=4-6\end{array}$ \\
\hline
\end{tabular}

$\mathrm{SD}=$ standard deviation. Race/ethnicity was noted as either White, Black, Latino/a, Asian, or selfdescribed/other. A more description of demographics within each sex and orientation group can be found in Safron et al. $(2017,2018)$.

\section{Stimuli and Procedure}

All participants underwent two experimental paradigms in the scanner: 1) viewing erotic pictures for around twenty minutes, and 2) viewing erotic videos (including both visual and auditory components) for around twenty minutes. Pictures depicted either nude individuals (women or men) or same-sex couples interacting sexually (female-female or male-male pairs).

Videos featured individual men or women self-stimulating. Pictures were shown for 3.5 seconds each, with variable-duration fixation crosses shown between images. Videos were shown for 15 seconds each, with 15-second distraction tasks in between. Neutral nature videos were also 
shown in order to estimate baseline responses. More information about the fMRI procedure and stimuli can be found in Safron et al. (2018, 2017).

Data collection for this study was originally designed to compare reward-related brain activity between individuals of different sexual orientations (Safron et al., 2018, 2017), and thus involved erotic stimuli. Although erotic stimuli are not typically used for social cognition tasks, activity in social-cognition related brain areas toward erotic stimuli would be consistent with more complex social cognition in sexual contexts.

\section{Data acquisition and preprocessing}

\section{Image acquisition, signal extraction, and fMRI preprocessing}

Technical specifications for our collection of $\mathrm{T} 1-$ and $\mathrm{T} 2 *$-weighted images are described in Safron et al. (2017, 2018). Image preprocessing for functional volumes is also described in Safron $(2017,2018)$.

\section{MRI preprocessing}

Preprocessing of MRI data was performed using the CAT12 toolbox (http://dbm.neuro.uni-jena.de/cat12/) and SPM12 (Statistical Parametric Mapping, Wellcome Trust Centre for Neuroimaging, http://www.fil.ion.ucl.ac.uk/spm) run on Matlab R2018a (Mathworks, Natick, MA, USA). Preprocessing steps were based on standard recommendations for CAT12 processing (Florian, Lüders, and Gaser, 2018) for voxel-based morphometry, described below.

Before preprocessing, image registration was assessed and adjusted visually. The origin point was set to the anterior commissure for each subject, and individual subject images were reoriented to match the template image. Participants' T1-weighted images were segmented into gray matter, white matter, and cerebrospinal fluid using SPM12 tissue probability maps and 
CAT12 default settings. To ensure image quality, one slice was displayed and visually reviewed for each image, and sample homogeneity was checked using default CAT12 settings. Twelve subjects with the lowest correlations were checked for artefacts and image quality, including three whose correlations were more than two standard deviations below average; no visible loss of quality was noted in any of these images. Images were smoothed using an $8 \times 8 \times 8$ full-widthat-half-maximum Gaussian kernel. Finally, total intracranial volume was calculated for each subject.

\section{Data Analysis}

\section{Data extraction for functional and structural ROI analyses}

We extracted data for both gray matter volume and activity using the same functionallydefined ROIs. ROIs were defined using maps from the Saxelab Social Cognitive Neuroscience Laboratory at MIT (Dufour et al., 2013) and displayed in bspmview (Figure 1). We used these functionally-defined ROIs for both functional and structural analyses in order to specifically focus on areas associated with social cognition. The rTPJ ROI covered the right angular gyrus, with a slight anterior extension into the superior temporal sulcus and a slight posterior extension into the neighboring anterior occipital lobe. The dmPFC ROI covered the medial portion of Brodmann area 9, with a slight lateral and inferior extension into Brodmann area 10.

\section{Figure 1}

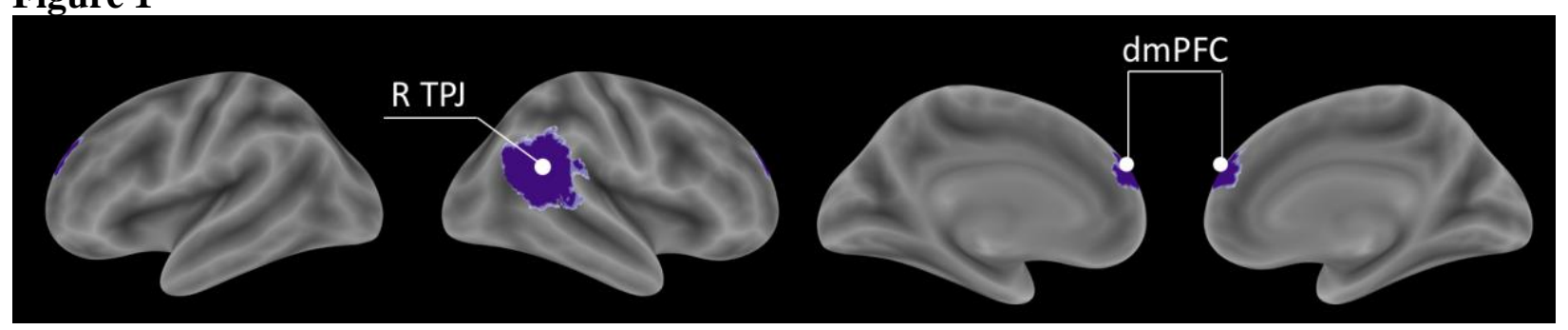

Social cognition related brain areas identified by and downloaded from the Saxelab, used as maps for functional and structural ROI analyses. $\mathrm{R}$ TPJ $=$ right temporoparietal junction, $\mathrm{dmPFC}=$ dorsomedial prefrontal cortex. 
We used the Marsbar toolbox to extract values for the rTPJ and dmPFC for functional data for four separate functional conditions: viewing erotic images of women, viewing erotic images of men, viewing erotic videos of women, and viewing erotic videos of men. Each of these contrasts had activations during a neutral baseline subtracted out. These contrasts are described in further detail in Safron et al. $(2018,2017)$. We also used the Marsbar toolbox to extract regional gray matter volumes within these rTPJ and dmPFC.

\section{ANCOVAs}

\section{Structural (regional volume) analyses in the rTPJ and dmPFC}

Following approaches taken by Ritchie et al. (2018), we performed ROI tests on the rTPJ and dmPFC both with and without correction for total intercranial volume (TIV). However, we primarily focused on analyses that corrected for TIV because we were interested in the ways in which social cognition areas may have been expanded relative to other areas in the brain between groups. In contrast, our secondary (TIV-uncorrected). results provide raw volume differences (corrected only for age), which did not account for how large these regions are relative to individual brain sizes.

TIV-Corrected ANCOVAs: A set of two 2x3 ANCOVAs was performed with independent factors of sex and sexual orientation, dependent factors of right TPJ and dmPFC volume, and participant age and total intracranial volume (TIV) included as covariates.

Follow-up ANCOVAs: We also performed follow-up ROI tests that were not corrected for total intracranial volume (TIV). Given past data showing larger global and regional brain volumes in men (Ritchie et al., 2018.), we expected both the right TPJ and dmPFC to be larger in our male participants. We did not have specific hypotheses about possible differences between sexual orientation groups in these analyses of raw regional differences. 


\section{Functional (brain activity) analyses in the rTPJ and dmPFC}

A set of eight 2x3 ANCOVAs was performed with independent factors of sex and sexual orientation. We tested right TPJ and dmPFC activation in response to four conditions: female erotic images, male erotic images, female erotic videos, male erotic videos, with neutral baselines subtracted from each. Participant age was included as a covariate.

\section{Results}

\section{ROI analyses}

\section{Structural Analyses}

TIV-Corrected ANCOVAs. After adjusting for age and total intracranial volume, there was a main effect of sex on dmPFC volume as well as a main effect of sexual orientation on right TPJ volume (Table 2a). Follow-up $t$-tests revealed that women showed larger dmPFC volumes than men, and heterosexual individuals showed larger right TPJs than homosexual individuals. An interaction effect of Sex x Sexual Orientation was present for the right TPJ, with heterosexual women showing larger right TPJs than homosexual women.

Contrary to our hypotheses, we did not find a significant main effect of orientation showing larger volumes for either the right TPJ or dmPFC in bisexuals, or an interaction effect revealing larger values in bisexual groups than in other groups.

Uncorrected ANCOVAs: A secondary set of tests was performed without correction for the total intracranial volume (TIV) of each participant, but with correction for participant age (Table 2b). These showed a main effect of sex for both the dmPFC and right TPJ, with men exhibiting greater raw volumes than women in these areas. There was no significant effect of sexual orientation, and no significant interaction effect of Sex x Orientation. 
Table 2a: Sex x Orientation Differences in Gray Matter Volume in the rTPJ and dmPFC

\begin{tabular}{|c|c|c|c|c|c|c|c|c|c|c|}
\hline & $\begin{array}{l}\mathrm{HeM} \\
\mathrm{N}= \\
26\end{array}$ & $\begin{array}{l}\text { BiM } \\
N \\
=28\end{array}$ & $\begin{array}{l}\text { HoM } \\
\text { N } \\
=24\end{array}$ & $\begin{array}{l}\mathrm{HeW} \\
\mathrm{N}= \\
25\end{array}$ & $\begin{array}{l}\mathrm{BiW} \\
\mathrm{N}= \\
26\end{array}$ & $\begin{array}{l}\text { HoW } \\
\text { N } \\
=24\end{array}$ & $\begin{array}{l}\text { Sex } \\
\text { f(df) } \\
\text { p-value }\end{array}$ & $\begin{array}{l}\text { Orientatio } \\
\text { n f(df) } \\
\text { p-value }\end{array}$ & $\begin{array}{l}\text { Sex* } \\
\text { Orientation } \\
\text { f(df) } \\
\text { p-value }\end{array}$ & Differences \\
\hline \multicolumn{11}{|l|}{ Region } \\
\hline $\begin{array}{l}\text { R Temporo- } \\
\text { parietal } \\
\text { junction } \\
(\mathrm{TPJ})\end{array}$ & $\begin{array}{l}.398 \\
\pm \\
.005\end{array}$ & $\begin{array}{l}.400 \\
\pm \\
.005\end{array}$ & $\begin{array}{l}.399 \\
\pm \\
.005\end{array}$ & $\begin{array}{l}0.417 \\
\pm \\
.005\end{array}$ & $\begin{array}{l}0.411 \\
\pm \\
.005\end{array}$ & $\begin{array}{l}0.392 \\
\pm \\
.005\end{array}$ & $\begin{array}{l}2.09(1,145) \\
p=0.151 \\
\eta p^{2}=0.014\end{array}$ & $\begin{array}{l}3.26(2,145) \\
p=.041 \\
\eta p^{2}=0.043\end{array}$ & $\begin{array}{l}.65(2,145) \\
p=.031 \\
\eta p^{2}=0.047\end{array}$ & $\begin{array}{l}\text { Orientation: heterosexual > } \\
\text { homosexual } \\
\text { Sex*Orientation: } \mathrm{HeW}>\mathrm{HoW}\end{array}$ \\
\hline $\begin{array}{l}\text { Dorsomedial } \\
\text { prefrontal } \\
\text { cortex } \\
(\text { dmPFC) }\end{array}$ & $\begin{array}{l}.381 \\
\pm \\
.007\end{array}$ & $\begin{array}{l}.381 \\
\pm \\
.007\end{array}$ & $\begin{array}{l}.381 \\
\pm \\
.007\end{array}$ & $\begin{array}{l}.418 \\
\pm \\
.007\end{array}$ & $\begin{array}{l}.403 \\
\pm \\
.007\end{array}$ & $\begin{array}{l}.390 \\
\pm \\
.007\end{array}$ & $\begin{array}{l}9.80(1,144) \\
p=0.002 \\
\eta p^{2}=0.064\end{array}$ & $\begin{array}{l}2.04(2,144) \\
\mathrm{p}=0.134 \\
\eta p^{2}=0.028\end{array}$ & $\begin{array}{l}2.03(2,144) \\
\mathrm{p}=0.135 \\
\eta p^{2}=0.0274\end{array}$ & Sex: Female > Male \\
\hline
\end{tabular}

$\mathrm{R}=$ right. $\mathrm{ROI}=$ region of interest. $\mathrm{HeM}=$ heterosexual men, $\mathrm{BiM}=$ bisexual men, $\mathrm{HoM}=$ homosexual men, $\mathrm{HeW}=$ heterosexual women, $\mathrm{BiW}=$ bisexual women, HoW = homosexual women. Parameter estimates of mean volume along with standard error are included for each group, adjusted for participant age and TIV.

Table 2b: Follow Up Analyses: Sex x Orientation Differences in Gray Matter Volume in the rTPJ and dmPFC, Without Correction for Total Intracranial Volume

\begin{tabular}{|c|c|c|c|c|c|c|c|c|c|c|}
\hline & $\begin{array}{l}\mathrm{HeM} \\
\mathrm{N}= \\
26\end{array}$ & $\begin{array}{l}\text { BiM } \\
\text { N } \\
=28\end{array}$ & $\begin{array}{l}\text { HoM } \\
\text { N } \\
=24\end{array}$ & $\begin{array}{l}\mathrm{HeW} \\
\mathrm{N}= \\
25\end{array}$ & $\begin{array}{l}\mathrm{BiW} \\
\mathrm{N}= \\
26\end{array}$ & $\begin{array}{l}\text { HoW } \\
\text { N } \\
=24\end{array}$ & $\begin{array}{l}\text { Sex } \\
\text { f(df) } \\
\text { p-value }\end{array}$ & $\begin{array}{l}\text { Orientatio } \\
\text { n f(df) } \\
\text { p-value }\end{array}$ & $\begin{array}{l}\text { Sex* } \\
\text { Orientation } \\
\text { f(df) } \\
\text { p-value }\end{array}$ & Differences \\
\hline \multicolumn{11}{|l|}{ Region } \\
\hline $\begin{array}{l}\text { R Temporo- } \\
\text { parietal } \\
\text { junction } \\
\text { (TPJ) }\end{array}$ & $\begin{array}{l}.427 \\
\pm \\
.008\end{array}$ & $\begin{array}{l}.425 \\
\pm \\
.008\end{array}$ & $\begin{array}{l}.416 \\
\pm \\
.008\end{array}$ & $\begin{array}{l}0.392 \\
\pm \\
.008\end{array}$ & $\begin{array}{l}0.381 \\
\pm \\
.008\end{array}$ & $\begin{array}{l}0.372 \\
\pm \\
.009\end{array}$ & $\begin{array}{l}33.31(1,146) \\
p<.001 \\
\eta p^{2}=0.186\end{array}$ & $\begin{array}{l}1.80(2,146) \\
\mathrm{p}=.168 \\
\eta \mathrm{p}^{2}=0.024\end{array}$ & $\begin{array}{l}.154(2,145) \\
\mathrm{p}=.858 \\
\eta p^{2}=0.002\end{array}$ & Sex: Male > Female \\
\hline $\begin{array}{l}\text { Dorsomedial } \\
\text { prefrontal } \\
\text { cortex } \\
\text { (dmPFC) }\end{array}$ & $\begin{array}{l}.406 \\
\pm \\
.009\end{array}$ & $\begin{array}{l}.402 \\
\pm \\
.009\end{array}$ & $\begin{array}{l}.395 \\
\pm \\
.009\end{array}$ & $\begin{array}{l}.397 \\
\pm \\
.009\end{array}$ & $\begin{array}{l}.378 \\
\pm \\
.009\end{array}$ & $\begin{array}{l}.373 \\
\pm \\
.009\end{array}$ & $\begin{array}{l}\text { 5.61(1,145) } \\
p=0.019 \\
\eta p^{2}=0.037\end{array}$ & $\begin{array}{l}1.97(2,145) \\
p=0.144 \\
\eta p^{2}=0.026\end{array}$ & $\begin{array}{l}.452(2,145) \\
\mathrm{p}=0.637 \\
\eta p^{2}=0.006\end{array}$ & Sex: Male > Female \\
\hline
\end{tabular}

$\mathrm{R}=$ right. $\mathrm{HeM}=$ heterosexual men, $\mathrm{BiM}=$ bisexual men, $\mathrm{HoM}=$ homosexual men, $\mathrm{HeW}=$ heterosexual women, $\mathrm{BiW}=$ bisexual women, HoW = homosexual women. Parameter estimates of mean volume along with standard error are included for each group, adjusted for participant age (but not TIV).

\section{Functional Analyses}

After adjusting for age, there were no main effects of either sex or sexual orientation on brain activity in the dmPFC or right TPJ for any of the four stimuli conditions tested (erotic pictures of women, erotic pictures of men, erotic videos of women, and erotic videos of men) 
(Table 3). We found only one Sex x Sexual orientation interaction effect for rTPJ activity:

toward erotic videos of women. However, follow-up t-tests (Tukey's HSD-corrected) did not reveal any differences between groups. Although significant differences were not found, it may be worth noting that group means for this condition did not go in the direction we expected: heterosexual men had the largest rTPJ responses toward videos of women, while bisexual women had the smallest rTPJ responses toward videos of women.

Overall, contrary to our hypotheses, we found neither main effects of orientation showing more activity in the right TPJ and dmPFC in bisexual individuals nor interaction effects revealing more activity in bisexual groups.

Table 3: Sex x Orientation Differences in Neural Activity Toward Erotic Stimuli in Two Social-Cognition Related Brain Regions

\begin{tabular}{|c|c|c|c|c|c|c|c|c|c|c|}
\hline & $\begin{array}{l}\mathrm{HeM} \\
\mathrm{N}= \\
26\end{array}$ & $\begin{array}{l}\mathrm{BiM} \\
\mathrm{N}= \\
28\end{array}$ & $\begin{array}{l}\mathrm{HoM}_{-} \\
\mathrm{N}= \\
24\end{array}$ & $\begin{array}{l}\text { HeW } \\
N= \\
25\end{array}$ & $\begin{array}{l}\mathrm{BiW} \\
\mathrm{N}= \\
26\end{array}$ & $\begin{array}{l}\text { HoW } \\
\mathrm{N}= \\
24\end{array}$ & $\begin{array}{l}\text { Sex } \\
\text { f(df) } \\
\text { p-value } \\
\eta p^{2}\end{array}$ & $\begin{array}{l}\text { Orientation } \\
f(d f) \\
p \text {-value } \\
\eta p^{2}\end{array}$ & $\begin{array}{l}\text { Sex* } \\
\text { Orientation } \\
\text { f(df) } \\
\text { p-value } \\
\eta p^{2}\end{array}$ & Differences \\
\hline \multicolumn{11}{|c|}{ Response to Pictures of Women } \\
\hline $\begin{array}{l}\text { R Temporo- } \\
\text { parietal } \\
\text { junction } \\
(\mathrm{TPJ})\end{array}$ & $\begin{array}{l}.105 \\
\pm \\
.069\end{array}$ & $\begin{array}{l}-.028 \\
\pm \\
.072\end{array}$ & $\begin{array}{l}-.091 \\
\pm \\
.070\end{array}$ & $\begin{array}{l}-.124 \\
\pm \\
.069\end{array}$ & $\begin{array}{l}.028 \\
\pm \\
.069\end{array}$ & $\begin{array}{l}-.043 \\
\pm \\
.073\end{array}$ & $\begin{array}{l}.481(1,146) \\
p=0.489 \\
\eta p^{2}=0.000\end{array}$ & $\begin{array}{l}.540(2,146) \\
\mathrm{p}=0.584 \\
\eta p^{2}=0.000\end{array}$ & $\begin{array}{l}2.71(2,146) \\
\mathrm{p}=0.070 \\
\eta p^{2}=0.000\end{array}$ & none \\
\hline $\begin{array}{l}\text { Dorsomedial } \\
\text { prefrontal } \\
\text { cortex } \\
(\text { dmPFC) }\end{array}$ & $\begin{array}{l}-.131 \\
\pm \\
.086\end{array}$ & $\begin{array}{l}-.259 \\
\pm \\
.090\end{array}$ & $\begin{array}{l}-.307 \\
\pm \\
.088\end{array}$ & $\begin{array}{l}-.314 \\
\pm \\
.090\end{array}$ & $\begin{array}{l}-.152 \\
\pm \\
.088\end{array}$ & $\begin{array}{l}-.426 \\
\pm \\
.091\end{array}$ & $\begin{array}{l}.731(1,144) \\
\mathrm{p}=0.394 \\
\eta p^{2}=0.005\end{array}$ & $\begin{array}{l}2.02(2,144) \\
p=0.137 \\
\eta p^{2}=0.027\end{array}$ & $\begin{array}{l}1.52(2,144) \\
p=0.223 \\
\eta p^{2}=0.021\end{array}$ & none \\
\hline \multicolumn{11}{|c|}{ Responses to Pictures of Men } \\
\hline $\begin{array}{l}\text { R Temporo- } \\
\text { parietal } \\
\text { junction } \\
\text { (TPJ) }\end{array}$ & $\begin{array}{l}.116 \\
\pm \\
.067\end{array}$ & $\begin{array}{l}.036 \\
\pm \\
.070\end{array}$ & $\begin{array}{l}.019 \\
\pm \\
.069\end{array}$ & $\begin{array}{l}.027 \\
\pm \\
.069\end{array}$ & $\begin{array}{l}.130 \\
\pm \\
.068\end{array}$ & $\begin{array}{l}.014 \\
\pm \\
.071\end{array}$ & $\begin{array}{l}.007(1,146) \\
\mathrm{p}=0.933 \\
\eta p^{2}=0.000\end{array}$ & $\begin{array}{l}.773(2,146) \\
\mathrm{p}=0.464 \\
\eta p^{2}=0.010\end{array}$ & $\begin{array}{l}1.63(2,146) \\
\mathrm{p}=0.200 \\
\eta p^{2}=0.022\end{array}$ & none \\
\hline $\begin{array}{l}\text { Dorsomedial } \\
\text { prefrontal } \\
\text { cortex } \\
(\text { dmPFC) }\end{array}$ & $\begin{array}{l}-.175 \\
\pm \\
.086\end{array}$ & $\begin{array}{l}-.223 \\
\pm \\
.090\end{array}$ & $\begin{array}{l}-.193 \\
\pm \\
.088\end{array}$ & $\begin{array}{l}-.263 \\
\pm \\
.090\end{array}$ & $\begin{array}{l}. .104 \\
\pm \\
.088\end{array}$ & $\begin{array}{l}-.436 \\
\pm \\
.091\end{array}$ & $\begin{array}{l}.859(1,144) \\
\mathrm{p}=0.356 \\
\eta p^{2}=0.006\end{array}$ & $\begin{array}{l}1.49(2,144) \\
\mathrm{p}=0.228 \\
\eta p^{2}=0.020\end{array}$ & $\begin{array}{l}2.15(2,144) \\
p=0.120 \\
\eta p^{2}=0.029\end{array}$ & none \\
\hline esponses t & S & & & & & & & & & \\
\hline
\end{tabular}




\begin{tabular}{|c|c|c|c|c|c|c|c|c|c|c|}
\hline $\begin{array}{l}\text { R Temporo- } \\
\text { parietal } \\
\text { junction } \\
\text { (TPJ) }\end{array}$ & $\begin{array}{l}.534 \\
\pm \\
.086\end{array}$ & $\begin{array}{l}.282 \\
\pm \\
.088\end{array}$ & $\begin{array}{l}.218 \\
\pm \\
.088\end{array}$ & $\begin{array}{l}.293 \\
\pm \\
.087\end{array}$ & $\begin{array}{l}.186 \\
\pm \\
.087\end{array}$ & $\begin{array}{l}.467 \\
\pm \\
.093\end{array}$ & $\begin{array}{l}.153(1,147) \\
\mathrm{p}=0.696 \\
\eta \mathrm{p}^{2}=0.001\end{array}$ & $\begin{array}{l}2.18(2,147) \\
\mathrm{p}=0.117 \\
\eta \mathrm{p}^{2}=0.029\end{array}$ & $\begin{array}{l}4.08(2,147) \\
p=0.019 \\
\eta p^{2}=0.053\end{array}$ & $\begin{array}{l}\text { Sex*Orientation: } \\
\text { significant } \\
\text { interaction effect, } \\
\text { but no differences } \\
\text { in follow up t- } \\
\text { tests (Tukey's } \\
\text { HSD corrected) }\end{array}$ \\
\hline $\begin{array}{l}\text { Dorsomedial } \\
\text { prefrontal } \\
\text { cortex } \\
(\text { dmPFC })\end{array}$ & $\begin{array}{l}-.062 \\
\pm \\
.101\end{array}$ & $\begin{array}{l}. .145 \\
\pm \\
.104\end{array}$ & $\begin{array}{l}-.360 \\
\pm \\
.103\end{array}$ & $\begin{array}{l}-.164 \\
\pm \\
.102\end{array}$ & $\begin{array}{l}.293 \\
\pm \\
.102\end{array}$ & $\begin{array}{l}-.245 \\
\pm \\
.109\end{array}$ & $\begin{array}{l}.260(1,147) \\
p=0.611 \\
\eta p^{2}=0.002\end{array}$ & $\begin{array}{l}1.71(2,147) \\
\mathrm{p}=0.185 \\
\eta \mathrm{p}^{2}=0.023\end{array}$ & $\begin{array}{l}.913(2,147) \\
\mathrm{p}=0.404 \\
\eta \mathrm{p}^{2}=0.012\end{array}$ & none \\
\hline \multicolumn{11}{|c|}{ Responses to Videos of Men } \\
\hline $\begin{array}{l}\text { R Temporo- } \\
\text { parietal } \\
\text { junction } \\
\text { (TPJ) }\end{array}$ & $\begin{array}{l}.456 \\
\pm \\
.089\end{array}$ & $\begin{array}{l}.221 \\
\pm \\
.092\end{array}$ & $\begin{array}{l}.176 \\
\pm \\
.091\end{array}$ & $\begin{array}{l}.242 \\
\pm \\
.090\end{array}$ & $\begin{array}{l}.148 \\
\pm \\
.090\end{array}$ & $\begin{array}{l}.357 \\
\pm \\
.097\end{array}$ & $\begin{array}{l}.206(1,147) \\
p=0.651 \\
\eta p^{2}=0.001\end{array}$ & $\begin{array}{l}1.67(2,147) \\
\mathrm{p}=0.191 \\
\eta \mathrm{p}^{2}=0.022\end{array}$ & $\begin{array}{l}2.40(2,147) \\
0.095 \\
\eta p^{2}=0.032\end{array}$ & none \\
\hline $\begin{array}{l}\text { Dorsomedial } \\
\text { prefrontal } \\
\text { cortex } \\
(\text { dmPFC })\end{array}$ & $\begin{array}{l}-.106 \\
\pm \\
.110\end{array}$ & $\begin{array}{l}-.249 \\
\pm \\
.104\end{array}$ & $\begin{array}{l}-.331 \\
\pm \\
.103\end{array}$ & $\begin{array}{l}-.169 \\
\pm \\
.102\end{array}$ & $\begin{array}{l}-.307 \\
\pm \\
.102\end{array}$ & $\begin{array}{l}-.337 \\
\pm \\
.109\end{array}$ & $\begin{array}{l}.232(1,147) \\
p=0.631 \\
\eta p^{2}=0.002\end{array}$ & $\begin{array}{l}1.94(2,147) \\
0.147 \\
\eta p^{2}=0.026\end{array}$ & $\begin{array}{l}.047(2,147) \\
0.954 \\
\eta p^{2}=0.001\end{array}$ & none \\
\hline
\end{tabular}

$\mathrm{R}=$ right. $\mathrm{HeM}=$ heterosexual men, $\mathrm{BiM}=$ bisexual men, $\mathrm{HoM}=$ homosexual men, $\mathrm{HeW}=$ heterosexual women, $\mathrm{BiW}=$ bisexual women, $\mathrm{HoW}=$ homosexual women. Parameter estimates of mean functional activity (with a neutral baseline condition removed) are provided along with standard error for each group, adjusted for participant age.

\section{Discussion}

We did not find support for our hypotheses: bisexuals had neither larger volumes nor more activity in two areas of the brain related to social cognition (the rTPJ and the dmPFC). Although we did not find evidence to support our hypotheses, we found other significant differences between sex/gender and sexual orientation groups. In terms of sex/gender differences, women had more (relative to total brain volume) dmPFC gray matter, and men had more raw dmPFC and rTPJ gray matter. These findings are consistent with prior large-scale studies of sex differences in brain structure, which have shown that men tend to have larger raw volumes across the cortex (Ritchie et al., 2018; Ruigrok et al., 2014), and that women tend to have larger relative (i.e. proportional) medial prefrontal regions compared with observation for men (Lotze et al., 2019).

In terms of sexual orientation group differences, we found that heterosexual women had larger gray matter volumes in their rTPJ than was observed in homosexual women. The 
significance of this finding is unclear. However, past research has shown higher empathizing abilities among heterosexual than homosexual women, which was specifically found to correspond to rTPJ activity (Perry et al., 2013). Future studies of empathy and sexual orientation may consider interactions of sexuality and empathy throughout life. For example, does having particularly high empathy cause individuals to relate to their same-sex and other-sex peers differently in childhood? How might being in relationships with men, women, or individuals of both genders influence tend to individuals' empathic abilities?

It is difficult to interpret the significance of our null findings concerning bisexuality and neural markers of social cognition. The most obvious possibility to consider (besides insufficient sample size) is that bisexuals and monosexuals do not actually tend to differ in their social cognition. However, it is also possible that there are average differences between bisexuals' and monosexuals' social cognition, but that these would be better approached using different brain regions, analysis methods (e.g. utilizing functional localizers or multivoxel techniques), or experimental paradigms. In terms of other brain regions that may be relevant to sexuality and social cognition, future work may wish to examine differences in the ventromedial prefrontal cortex (vmPFC) in the context of studies explicitly involving empathic processing (Saxe, 2006). Other social cognition related areas that may be of interest include the extrastriate body area and the superior temporal sulcus, both of which have been associated with perceiving and interpreting human actions (A_moruso_et_al.,_2011;_Astafiev_et

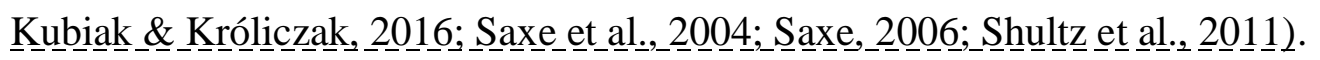

With respect to analysis methods with potential relevance for understanding sexual orientation, novel approaches involving network flexibility (Bassett et al., 2011; Betzel et al., 2017) may (perhaps intuitively) allow for the detection of brain network features corresponding 
to flexibility in behavior and cognition. A potential question for future research is whether increased network flexibility corresponds to more complex and flexible social cognition, and whether this differs between individuals with more and less flexible sexual orientations. Finally, further longitudinal work on sexuality that considers both development (Xu et al., 2019) and adulthood (Diamond, 2008; Diamond et al., 2017) may be promising for revealing potential interactions between attraction patterns, sociality, personality, and sense of self and identity. We chose to report these null findings for two reasons. First, we wished to help contribute to avoiding the publication biases and their potential contributions to the replication crisis (Joober et al., 2012; Mlinarić et al., 2017). Another reason was that even though our analyses did not produce support for our hypotheses, we hope that some of the questions discussed in this paper may contribute to future discussions about sexuality, social cognition, and potential sources of differences between bisexuals and monosexuals. Specifically, we hope to see future investigations use novel approaches to considering relationships between sexuality and other aspects of individuals, such as the ways that personality characteristics might shape and be shaped by social and cultural contexts. 


\section{Author Contributions Statement}

D.S. and A.R. were responsible for data collection. A.S. was responsible for

developing the analysis approach. V.K and A.S analyzed the data and wrote the

manuscript. M.L. and M.W. provided neuroimaging analysis support. J.M.B. provided

domain expertise and guidance through all stages of research and manuscript

preparation. All authors have read and approved the final manuscript version.

\section{Competing Interests Statement}

The authors of this manuscript have no conflicts of interest or competing interests

relevant to this paper.

\section{References}

Abbot, E. S. (1916). The Causal Relations between Structure and Function in Biology. The American Journal of Psychology, 27(2), 245-250. JSTOR. https://doi.org/10.2307/1413176

Amoruso, L., Couto, J. B., \& Ibanez, A. (2011). Beyond Extrastriate Body Area (EBA) and Fusiform Body Area (FBA): Context Integration in the Meaning of Actions. Frontiers in Human Neuroscience, 5. https://doi.org/10.3389/fnhum.2011.00124

Anderson, E., \& McCormack, M. (2016). The Changing Dynamics of Bisexual Men's Lives: Social Research Perspectives. Springer International Publishing. https://doi.org/10.1007/978-3-319-29412-4

Astafiev, S. V., Stanley, C. M., Shulman, G. L., \& Corbetta, M. (2004). Extrastriate body area in human occipital cortex responds to the performance of motor actions. Nature Neuroscience, 7(5), 542-548. https://doi.org/10.1038/nn1241

Bassett, D. S., Wymbs, N. F., Porter, M. A., Mucha, P. J., Carlson, J. M., \& Grafton, S. T. (2011). Dynamic reconfiguration of human brain networks during learning. Proceedings of the National Academy of Sciences, 108(18), 7641-7646. https://doi.org/10.1073/pnas.1018985108

Beauchamp, M. S. (2015). The social mysteries of the superior temporal sulcus. Trends in Cognitive Sciences, 19(9), 489-490. https://doi.org/10.1016/j.tics.2015.07.002

Betzel, R. F., Satterthwaite, T. D., Gold, J. I., \& Bassett, D. S. (2017). Positive affect, surprise, and fatigue are correlates of network flexibility. Scientific Reports, 7(1), 520. https://doi.org/10.1038/s41598-017-00425-z

Bzdok, D., Langner, R., Schilbach, L., Engemann, D. A., Laird, A. R., Fox, P. T., \& Eickhoff, S. B. (2013). Segregation of the human medial prefrontal cortex in social cognition. Frontiers in Human Neuroscience, 7. https://doi.org/10.3389/fnhum.2013.00232

Carrington, S. J., \& Bailey, A. J. (2009). Are there theory of mind regions in the brain? A review of the neuroimaging literature. Human Brain Mapping, 30(8), 2313-2335. https://doi.org/10.1002/hbm.20671

Chan, R. C. H., Operario, D., \& Mak, W. W. S. (2020). Bisexual individuals are at greater risk of poor mental health than lesbians and gay men: The mediating role of sexual identity stress at multiple levels. Journal of Affective Disorders, 260, 292-301. https://doi.org/10.1016/j.jad.2019.09.020

Cook, N. D. (2018). The Triadic Roots of Human Cognition: "Mind" Is the Ability to go Beyond Dyadic Associations. Frontiers in Psychology, 9. https://doi.org/10.3389/fpsyg.2018.01060 
Diamond, L. M. (2008). Female bisexuality from adolescence to adulthood: Results from a 10-year longitudinal study. Developmental Psychology, 44(1), 5-14. https://doi.org/10.1037/0012-1649.44.1.5

Diamond, Lisa M., Dickenson, J. A., \& Blair, K. L. (2017). Stability of Sexual Attractions Across Different Timescales: The Roles of Bisexuality and Gender. Archives of Sexual Behavior, 46(1), 193-204. https://doi.org/10.1007/s10508-016-0860-x

Diamond, L.M. (2008). Sexual Fluidity: Understanding Women's Love and Desire. Harvard University Press.

Dufour, N., Redcay, E., Young, L., Mavros, P. L., Moran, J. M., Triantafyllou, C., Gabrieli, J. D. E., \& Saxe, R. (2013). Similar brain activation during false belief tasks in a large sample of adults with and without autism. PloS One, 8(9), e75468. https://doi.org/10.1371/journal.pone.0075468

Feinstein, B. A., \& Dyar, C. (2017). Bisexuality, minority stress, and health. Current Sexual Health Reports, 9(1), 42-49. https://doi.org/10.1007/s11930-017-0096-3

Fernald, R. D. (2003). How does Behavior Change the Brain? Multiple Methods to Answer Old Questions. Integrative and Comparative Biology, 43(6), 771-779. https://doi.org/10.1093/icb/43.6.771

Fjell, A. M., \& Walhovd, K. B. (2010). Structural brain changes in aging: Courses, causes and cognitive consequences. Reviews in the Neurosciences, 21(3), 187-221. https://doi.org/10.1515/revneuro.2010.21.3.187

Fleischman, D. S., Fessler, D. M. T., \& Cholakians, A. E. (2014). Testing the Affiliation Hypothesis of Homoerotic Motivation in Humans: The Effects of Progesterone and Priming. Archives of Sexual Behavior, 44(5), 1395-1404. https://doi.org/10.1007/s10508-014-0436-6

Galupo, M. P., Mitchell, R. C., \& Davis, K. S. (2015). Sexual minority self-identification: Multiple identities and complexity. Psychology of Sexual Orientation and Gender Diversity, 2(4), 355-364. https://doi.org/10.1037/sgd0000131

Gweon, H., Dodell-Feder, D., Bedny, M., \& Saxe, R. (2012). Theory of mind performance in children correlates with functional specialization of a brain region for thinking about thoughts. Child Development, 83(6), 1853-1868. https://doi.org/10.1111/j.1467-8624.2012.01829.x

Hassabis, D., Spreng, R. N., Rusu, A. A., Robbins, C. A., Mar, R. A., \& Schacter, D. L. (2014). Imagine All the People: How the Brain Creates and Uses Personality Models to Predict Behavior. Cerebral Cortex, 24(8), 1979-1987. https://doi.org/10.1093/cercor/bht042

Joober, R., Schmitz, N., Annable, L., \& Boksa, P. (2012). Publication bias: What are the challenges and can they be overcome? Journal of Psychiatry \& Neuroscience : JPN, 37(3), 149-152. https://doi.org/10.1503/jpn.120065

Kolb, B., \& Gibb, R. (2011). Brain Plasticity and Behaviour in the Developing Brain. Journal of the Canadian Academy of Child and Adolescent Psychiatry, 20(4), 265-276.

Koster-Hale, J., Richardson, H., Velez, N., Asaba, M., Young, L., \& Saxe, R. (2017). Mentalizing regions represent distributed, continuous, and abstract dimensions of others' beliefs. NeuroImage, 161, 9-18. https://doi.org/10.1016/j.neuroimage.2017.08.026

Kubiak, A., \& Króliczak, G. (2016). Left extrastriate body area is sensitive to the meaning of symbolic gesture: Evidence from fMRI repetition suppression. Scientific Reports, 6(1), 1-13. https://doi.org/10.1038/srep31064

Lieberman, M. D., Straccia, M. A., Meyer, M. L., Du, M., \& Tan, K. M. (2019). Social, self, (situational), and affective processes in medial prefrontal cortex (MPFC): Causal, multivariate, and reverse inference evidence. Neuroscience and Biobehavioral Reviews, 99, 311-328. https://doi.org/10.1016/j.neubiorev.2018.12.021

Lotze, M., Domin, M., Gerlach, F. H., Gaser, C., Lueders, E., Schmidt, C. O., \& Neumann, N. (2019). Novel findings from 2,838 Adult Brains on Sex Differences in Gray Matter Brain Volume. Scientific Reports, 9(1), 1-7. https://doi.org/10.1038/s41598-018-38239-2

Lübke, K. T., Sachse, C., Hoenen, M., \& Pause, B. M. (2019). Mu-Suppression as an Indicator of Empathic Processes in Lesbian, Gay, and Heterosexual Adults. Archives of Sexual Behavior. https://doi.org/10.1007/s10508-019-01491-2

Mlinarić, A., Horvat, M., \& Šupak Smolčić, V. (2017). Dealing with the positive publication bias: Why you should really publish your negative results. Biochemia Medica, 27(3). https://doi.org/10.11613/BM.2017.030201

Nettle, D. (2007). Empathizing and systemizing: What are they, and what do they contribute to our understanding of psychological sex differences? British Journal of Psychology, 98(2), 237-255. https://doi.org/10.1348/000712606X117612 
Perry, D., Walder, K., Hendler, T., \& Shamay-Tsoory, S. G. (2013). The gender you are and the gender you like: Sexual preference and empathic neural responses. Brain Research, 1534, 66-75. https://doi.org/10.1016/j.brainres.2013.08.040

Rahman, Q., Wilson, G. D., \& Abrahams, S. (2004). Sex, sexual orientation, and identification of positive and negative facial affect. Brain and Cognition, 54(3), 179-185. https://doi.org/10.1016/j.bandc.2004.01.002

Ritchie, S. J., Cox, S. R., Shen, X., Lombardo, M. V., Reus, L. M., Alloza, C., Harris, M. A., Alderson, H. L., Hunter, S., Neilson, E., Liewald, D. C. M., Auyeung, B., Whalley, H. C., Lawrie, S. M., Gale, C. R., Bastin, M. E., McIntosh, A. M., \& Deary, I. J. (n.d.). Sex Differences in the Adult Human Brain: Evidence from 5216 UK Biobank Participants. Cerebral Cortex. https://doi.org/10.1093/cercor/bhy109

Ritchie, S. J., Cox, S. R., Shen, X., Lombardo, M. V., Reus, L. M., Alloza, C., Harris, M. A., Alderson, H. L., Hunter, S., Neilson, E., Liewald, D. C. M., Auyeung, B., Whalley, H. C., Lawrie, S. M., Gale, C. R., Bastin, M. E., McIntosh, A. M., \& Deary, I. J. (2018). Sex Differences in the Adult Human Brain: Evidence from 5216 UK Biobank Participants. Cerebral Cortex (New York, N.Y.: 1991), 28(8), 2959-2975. https://doi.org/10.1093/cercor/bhy109

Ruben, M. A., Hill, K. M., \& Hall, J. A. (2014). How women's sexual orientation guides accuracy of interpersonal judgements of other women. Cognition and Emotion, 28(8), 1512-1521. https://doi.org/10.1080/02699931.2014.890093

Ruigrok, A. N. V., Salimi-Khorshidi, G., Lai, M.-C., Baron-Cohen, S., Lombardo, M. V., Tait, R. J., \& Suckling, J. (2014). A meta-analysis of sex differences in human brain structure. Neuroscience and Biobehavioral Reviews, 39(100), 34-50. https://doi.org/10.1016/j.neubiorev.2013.12.004

Safron, A., Klimaj, V., Sylva, D., Rosenthal, A. M., Li, M., Walter, M., \& Bailey, J. M. (2018). Neural Correlates of Sexual Orientation in Heterosexual, Bisexual, and Homosexual Women. Scientific Reports, 8. https://doi.org/10.1038/s41598-017-18372-0

Safron, A., Sylva, D., Klimaj, V., Rosenthal, A. M., Li, M., Walter, M., \& Bailey, J. M. (2017). Neural Correlates of Sexual Orientation in Heterosexual, Bisexual, and Homosexual Men. Scientific Reports, 7. https://doi.org/10.1038/srep41314

Saxe, R, \& Kanwisher, N. (2003). People thinking about thinking peopleThe role of the temporo-parietal junction in "theory of mind." NeuroImage, 19(4), 1835-1842. https://doi.org/10.1016/S1053-8119(03)00230-1

Saxe, R, Xiao, D.-K., Kovacs, G., Perrett, D. I., \& Kanwisher, N. (2004). A region of right posterior superior temporal sulcus responds to observed intentional actions. Neuropsychologia, 42(11), 1435-1446. https://doi.org/10.1016/j.neuropsychologia.2004.04.015

Saxe, Rebecca. (2006). Uniquely human social cognition. Current Opinion in Neurobiology, 16(2), 235-239. https://doi.org/10.1016/j.conb.2006.03.001

Saxe, Rebecca, \& Powell, L. J. (2006). It's the Thought That Counts: Specific Brain Regions for One Component of Theory of Mind. Psychological Science, 17(8), 692-699. https://doi.org/10.1111/j.1467-9280.2006.01768.x

Saxe, Rebecca, \& Wexler, A. (2005). Making sense of another mind: The role of the right temporo-parietal junction. Neuropsychologia, 43(10), 1391-1399. https://doi.org/10.1016/j.neuropsychologia.2005.02.013

Schurz, M., Radua, J., Aichhorn, M., Richlan, F., \& Perner, J. (2014). Fractionating theory of mind: A meta-analysis of functional brain imaging studies. Neuroscience \& Biobehavioral Reviews, 42, 9-34. https://doi.org/10.1016/j.neubiorev.2014.01.009

Shultz, S., Lee, S. M., Pelphrey, K., \& McCarthy, G. (2011). The posterior superior temporal sulcus is sensitive to the outcome of human and non-human goal-directed actions. Social Cognitive and Affective Neuroscience, 6(5), 602-611. https://doi.org/10.1093/scan/nsq087

Tomasello, M., Carpenter, M., Call, J., Behne, T., \& Moll, H. (2005). Understanding and sharing intentions: The origins of cultural cognition. Behavioral and Brain Sciences, 28(5), 675-691. https://doi.org/10.1017/S0140525X05000129

Van Overwalle, F. (2009). Social cognition and the brain: A meta-analysis. Human Brain Mapping, 30(3), 829-858. https://doi.org/10.1002/hbm.20547

Wagner, D. D., Haxby, J. V., \& Heatherton, T. F. (2012). The representation of self and person knowledge in the medial prefrontal cortex. Wiley Interdisciplinary Reviews. Cognitive Science, 3(4), 451-470. https://doi.org/10.1002/wcs.1183

Xu, Y., Norton, S., \& Rahman, Q. (2019). Early life conditions and adolescent sexual orientation: A prospective birth cohort study. Developmental Psychology, 55(6), 1226-1243. https://doi.org/10.1037/dev0000704

Yoshino, K. (2000). The Epistemic Contract of Bisexual Erasure. Stanford Law Review, 52(2), 353-461. JSTOR. https://doi.org/10.2307/1229482 